\title{
Extended draf IIb procedure in the treatment of unilateral frontal malignant tumor
}

\author{
Tengchin Wang* \\ Department of otolaryngology, Tainan municipal hospital, Tainan City, Taiwan
}

\begin{abstract}
Draf III procedure can be applied for intra-frontal sinus malignant lesions conventionally. But in the confined, predominantly unilateral lesions, Draf IIb procedure is an ideal choice which cause less damage to the normal tissues. We report unilateral sinonasal malignant case with frontal involved. The frontal lesion was removed by Draf IIb procedure and the outcome is well without leaving severe sequelae.
\end{abstract}

\section{Introduction}

Surgical resection is the main choice for sinonasal benign or malignant tumors. Traditionally, Draf III procedure can be performed to access the lesion inside the frontal sinus. In the case of confined, predominantly unilateral lesions, Draf IIb procedure provides wide access to the frontal sinus. This approach can be extended without destruction of the contralateral frontal sinus drainage pathway.

\section{Case report}

We report on a 52-year-old woman who suffered from right epistaxis, nasal obstruction and fetid odor discharge for 3 months. She received examination in our department, a papillomatous lesion with necrotic content was identified (Figure 1). Biopsy reports squamous cell carcinoma; SCC Antigen is elevating. Computed tomography displays a mass with central necrosis infiltrating the maxillary, ethmoid and frontal sinus; the medial maxillary wall is decayed and left frontal sinusitis is notable (Figure 2). We started operation by eradicating the tumor in the ethmoid, maxillary sinus. Once removing the tumor in the frontal recess, Draf IIb procedure was performed with an irrigated RAD

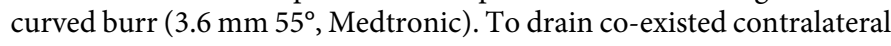
frontal sinusitis and gaining adequate marging, we extended Draf IIb procedure by removing lower intersinus septum, the lesion inside the frontal sinus doesn't infiltrate to the sinusal mucosa thus can be removed easily (Figure 3 ). There were no sequelas leaving in this patient. Post-operative followed-up exhibits no residual tumor, (Figure 4).

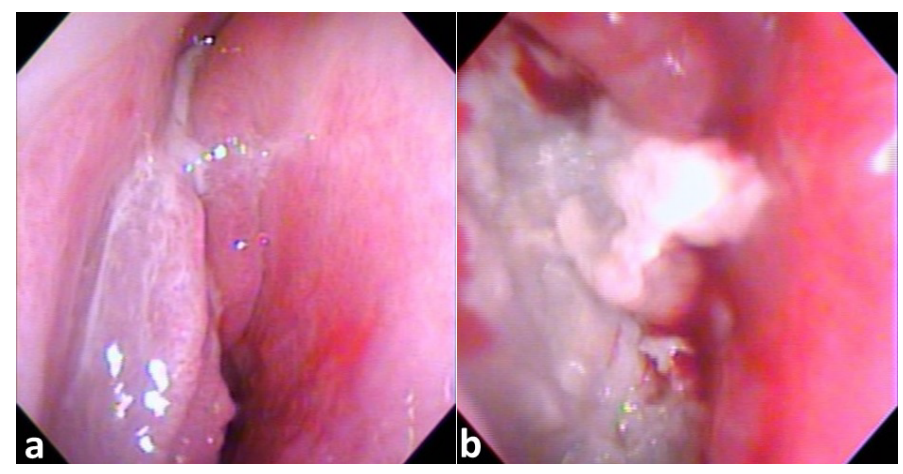

Figure 1. (a) Papillomatous lesion obstructs right nasal cavity (b)With necrotic material within the tumor.

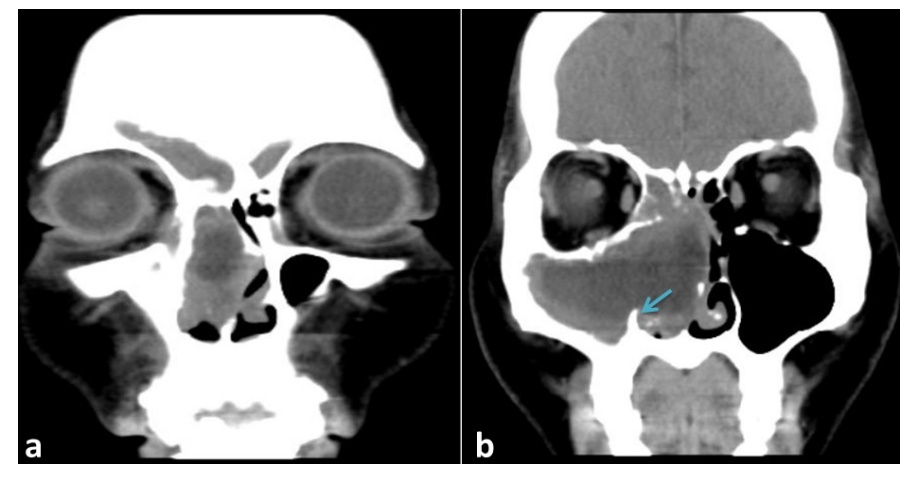

Figure 2. Right nasal tumor with central necrosis infiltrates maxillary, ethmoid and frontal sinus $(a, b)$; the medial maxillary wall is decayed (b. blue arrow).

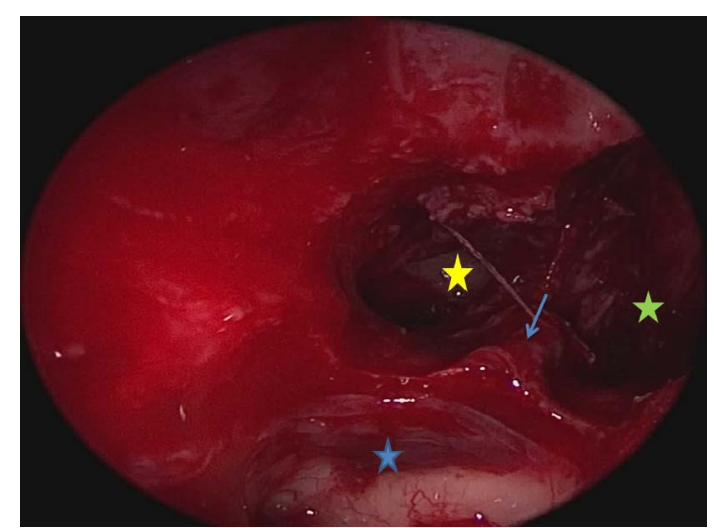

Figure 3. Draf IIb. 2 procedure includes removing tumor in the right frontal sinus and drain contralateral frontal sinusitis after lowing down intersinus septum (blue asterisk: suprabulla cell, yellow asterisk: right frontal sinus, green asterisk: left frontal sinus, blue arrow: intersinus septum).

Correspondence to: Tengchin Wang, Department of otolaryngology, Tainan municipal hospital No.670, Chong de Rd, East Dist, Tainan City 701, Taiwan, Tel: +8862609926;Email: tengchin27@hotmail.com

Key words: Draf IIb procedure

Received: November 13, 2017; Accepted: December 05, 2017; Published: December 09, 2017 


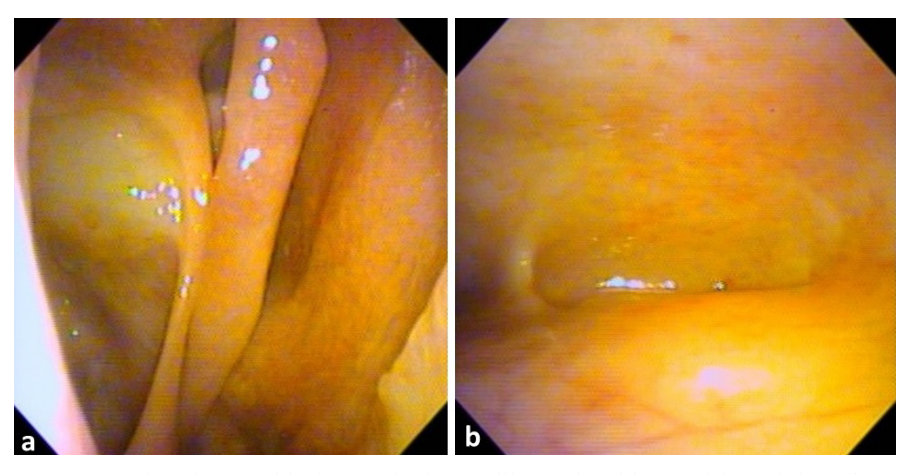

Figure 4. There is no residual tumor in the maxillary, ethmoid (a) and frontal sinus (b).

\section{Discussion and conclusion}

In the case of confined, unilateral frontal lesions, less destructive, limited approaches, defined as extended Draf IIb, can be applied without disturbing the contralateral frontal sinus drainage pathway according to literature. Gotlib et al. have classified extended Draf IIb procedure into 3 subtypes [1]; Extended Draf IIb.2 (or mini-Lothrop) refers to Draf IIb procedure with removal of the lower intersinus septum. This technique is applicable for bilateral frontal lesions with one side limiting in frontal sinus or unilateral frontal sinus disease with intersinus septum deviation towards the lesion. It minimizes destruction of the contralateral frontal sinus drainage pathway when comparing to Draf III. The nasal septum can be kept intact as compared to Draf IIb.1 and Draf IIb.3 procedures.

Selected cases of unilateral frontal sinus malignant disease can also be safely and effectively managed using extended Draf IIb procedure. This technique not only offers an appropriate margin of resection, but also leads to less surgical duration and tissue trauma than draf III procedure.

\section{Reference}

1. Gotlib T, Held-Ziółkowska M, Niemczyk K(2015) Extended draf IIb procedures in the treatment of frontal sinus pathology. Clin Exp Otorhinolaryngol 8: 34-38. [Crossref]

Copyright: $\odot 2017$ Nomura T. This is an open-access article distributed under the terms of the Creative Commons Attribution License, which permits unrestricted use, distribution, and reproduction in any medium, provided the original author and source are credited. 